\title{
Structural Relationships between Perceived Transformational Teaching and Critical Thinking: Mediating Role of Motivational Beliefs
}

\author{
Iranian Evolutionary and Educational \\ Psychology Journal \\ December 2020: 249-257 \\ (C) University of Hormozgan Publication 2020 \\ DOI: 10.29252/ieepj.2.4.249 \\ http://ieepj.hormozgan.ac.ir
}

\section{Zohreh Barzegar1, Qamar Kiani2*, Ali Shahnavaz $^{3}$}

\begin{abstract}
The purpose of present study was to examine the structural relationship between perceived transformational teaching and critical thinking mediated by motivational beliefs (self-efficacy, intrinsic interest and test anxiety) among university students. The population in this study was all of the undergraduate students of Psychology of Islamic Azad University, Karaj Branch, Iran, in 2019-2020 academic year. From this population 384 students were selected using random stratified sampling method. The research instruments were Transformational Teaching Questionnaire (TTQ), The California Critical Thinking Disposition (CCTD) questionnaire and Motivated Strategies for Learning Questionnaire (MSLQ). The proposed model of the relationships between variables was tested using path analysis. According to results, proposed model had an acceptable fitness regarding fitness indices. In general, the results showed that perceived transformational teaching are effective both directly and indirectly through self-efficacy, intrinsic interest and test anxiety with critical thinking disposition.
\end{abstract}

Keywords: Perceived Transformational Teaching, Critical Thinking, motivational beliefs, college Students

\section{Introduction}

With the increasing development of science and technology, educational systems have undergone extensive changes and transformations, and have prepared the ground for many changes through the development of science and thinking. These systems have always driven change. Transformational teaching prepares students to think in the face of different positive challenges (De Sousa, Rasmussen, and Pierroux, 2018). Teaching styles reflect dominant personal and behavioral characteristics of instructors manifested during class management (McEnroe-Petitte, and Farris, 2020). Therefore, it is imperative to change curricula goals, teaching materials and content, teaching methods and tools, and in general, all teaching and learning processes in order to keep pace with recent innovations. Transformational teaching is a kind of educational practice that can transform teachers, present them with new challenges, and may even give them new perspectives (Luyten and Bazo, 2019). Transformational teaching usually takes place in an educational setting where knowledge is passed on from a teacher to learners. In this approach, students can simply adapt themselves to their teacher to learn new

1. Ph.D Student, Department of Psychology, Zanjan Branch, Islamic Azad University, Zanjan, Iran

2. Assistant Professor, Department of Psychology, Zanjan Branch, Islamic Azad University, Zanjan, Iran, *Corresponding author email: Qamar.kiani@,iauz.ac.ir

3. Assistant Professor, Department of Mathematical Sciences, Zanjan Branch, Islamic Azad University, Zanjan, Iran 
knowledge. Transformational teaching emphasizes question and answer (Q\&A) strategy, critical thinking, and the development of a high level of thinking and communication skills. It allows students to recognize limitations related to their current knowledge and skills and provides them with the opportunity to try and apply new sets of knowledge and skills (Jabbari, 2017).

Transformational teaching provides students with critical thinking skills. Critical thinking is an essential skill in the new world that facilitates sensible participation in a healthy society (Karami, Rajaei, and Namkhah, 2014). The American Philosophical Association defines critical thinking as a purposeful and self-regulating judgment that is based on interpretation, analysis, inference, and explanation of situational, methodological, and conceptual considerations (Zhang and Chen, 2020). Educational systems often reveal learning outcomes based on academic achievements; therefore, students with high critical thinking skills are quite successful (Abdi Ansar, Fathi azar, and Abdollahi, 2015). Critical thinking a vital goal in higher education (Changwong, Sukkamart and Sisan, 2018) as well as an essential life skill in the modern world (Fajari, Sarwanto, and Chumdari, 2020). Critical thinking is a central competence for students in all academic and educational disciplines, which must be included as a key factor in academic curricula, especially in higher education curricula (Pai, Eng, and Ko, 2013) in order to advance innovation and knowledge production.

Critical thinking is a mental process that enables individuals to make wise decisions about different ideas, activities, and issues (khoshneshin langeroodi, 2015). Students who are not motivated enough cannot understand problems. Therefore, problems must arise from their real life, and any thinking must be related to realties. The main mission and goal of education is to train individuals who can think separately; people who do research, not just simply accept what is dictated to them (Seiahi Atabaki, Keshtiaray, and Yarmohammadian, 2016). People with critical thinking are open to new ideas and changes. They are also very flexible, creative, analytical, energetic, risk-taking, knowledgeable, and intuitive (Popil, 2011). Critical thinking helps teachers improve their teaching styles (Al-Degether, 2009).

In addition to transformational teaching style, students' motivational beliefs can also lead to the development of critical thinking skills. Motivation is an internal quality that stimulates, directs, and maintains efforts made by individuals to perform various tasks (Soltani arabshahi, Norouzi, Norouzi, and Cid, 2014). According to Niemiec, Ryan and Deci (2010) people who perceive themselves as self-sufficient and independent tend to have intrinsic motivations. Motivation is recognized as the strongest driving force in the context of academic hard work. The theory of self-organization is among the most important theories associated with motivation. This theory is based on the quality of motivation and according to Williams, different levels of motivation result in different motivation qualities as well as different outcomes. According to this theory, human beings naturally tend to move towards self-organization. The spectrum of motivation ranges from internal motivation to total reluctance (Kusurkar, Croiset, and ten Cate, 2011). Motivational beliefs are based on cultural and social context of societies. They are also major predictor of academic achievement (Buric and Kim, 2020). Intrinsic motivation orientation improves performance. This motivation is reinforced when self-regulatory needs are fulfilled, and is weakened when one is threatened with punishment, or is evaluated, stressed, commanded, and prohibited (Samadi, 2012). In fact, people with intrinsic motivations strive to acquire skills, competence, and a sense of pride (Samavi and Najjarpourian, 2019). Learners who perceive their competence, set their own goals, and regulate their own behavior have intrinsic motivation orientation. Intrinsic interest is a fundamental property possessed by successful academic people. External motivation orientation - as the opposite of 
intrinsic interest - reduces an individual's control over his/her perceived self-determination (Duty, Christian, Loftus, and Zappi, 2016).

Transformational teaching emphasizes the mediating role of motivational beliefs (e.g. self-efficacy, intrinsic interest, and test anxiety). In the discussion of motivation and learning, academic achievement is among behavioral outcomes of achievement goals. The goal achievement theory explains the effect of learning environment (such as teaching style) on students' motivation levels (Kavasan, 1996; Soltani Arabshahi, et al., 2014). Without an intrinsic interest, there would be neither a goal nor a self-driven guidance. Goal orientation is an unconscious strategy used to perform a learning task (Hoffman, Hudak-Rosander, Datta, Morris and Kelz, 2014). Learners with intrinsic interest are more likely to have higher levels of adaptive cognition, stronger motivational outcomes, and higher levels of academic achievement than their peers (Walters, 1998; quoted by Samadi, 2012).

Transformational teaching style significantly affects learners' self-efficacy. Self-efficacy is the expectation of an individual to successfully perform certain purposeful behaviors (Cheng, and et.al, 2020). It reflects a kind of ability to perform sustainably (Mustafa, Glavee-Geo, Gronhaug, and SaberAlmazrouei, 2019) and, despite its intrinsic nature it requires searching for information (Aharoni and Ghazit, 2020). Self-efficacy involves an individual's beliefs about his/her ability to perform tasks that can affect future life events (Stewart, Seifert, and Rolheiser, 2015). It also protects people against anxiety.

One of the main goals of an educational system is to evaluate students' learning performance through tests. Test anxiety emerges when an individual's memory is challenged (Mavilidi, Ouwehand, Riley, Chandler, and Paas, 2020). Individual characteristics such as self-efficacy can significantly affect test anxiety levels. A student may know answers to almost all questions, but he/she will not manage to write down those answers due to high levels of test anxiety (Saheb Alzamani and Zirak, 2011). Test anxiety is an unpleasant feeling or emotional state that people experience during formal exams or in other stressful situations. Test anxiety is a common type of school anxiety that seems to have emerged due to the increasing importance of tests in educational systems (MacDonald, 2001). This study aimed to develop a model to predict the structural relationship between transformational teaching style and critical thinking mediated by motivational beliefs of students.

\section{Material and Method}

In this correlational study, the study population consisted of all of the undergraduate students of Psychology of Islamic Azad University, Karaj Branch, Iran in the academic year of 2019-2020. From this population 384 students were selected using random stratified sampling method. Three questionnaires were used to collect data:

Transformational Teaching Questionnaire (TTQ): This 16-item questionnaire was developed by Beauchamp et al. (2000). The items are scored on a 5-point rating scale (0: not at all, 1: rarely, 2: sometimes, 3 : often, and 4: always), and the total score ranges from 0 to 64 . The questionnaire consists of four subscales designed to measure the four transformational teaching dimensions of idealized influence (4 items; for example, "Treats me in ways that build my respect"), inspirational motivation (4 items; for example, "Motivates me to try my hardest"), intellectual stimulation (4 items; for example, "Provides me with tasks and challenges that get me to think in different ways"), and individualized consideration (4 items; for example, "Recognizes the 
needs and abilities of each student in the class"). Beauchamp et al. (2000) reported an overall internal consistency of 0.96 for this questionnaire.

The California Critical Thinking Disposition (CCTD) questionnaire: consists of 75 items in the form of a 6 point Likert scale ranging from 'completely disagree' to 'completely agree.' There were seven subscales in CCTD questionnaire: truth-seeking (12 items), open-mindedness (12 items), analyticity (11 items), organizing (11 items), self-confidence (9 items), and maturity (10 items), and curiosity (10 items). The validity and reliability of this test has been demonstrated many times in previous studies (Facione and Facione ,1990). Motivated Strategies for Learning Questionnaire (MSLQ): This instrument was developed by Pintrich and De Groot (1990). It uses five-choice closed-ended items to measure motivational beliefs. The items range from strongly agree to strongly disagree. This scale includes three subscales of self-efficacy, intrinsic value, and test anxiety. Using Cronbach's alpha method, Pintrich and De Groot (1990) calculated three reliability values for this tool including 0.77, 0.64, and 0.68. The data were analyzed using in Amos using structural equation modeling.

\section{Results}

A total of $78.4 \%$ of the participants were male and $21.6 \%$ were female. The descriptive statistics, correlation coefficients, and Cronbach's alphas are presented in Table 1.

Table 1. Correlation matrix and descriptive statistics

\begin{tabular}{|c|c|c|c|c|c|}
\hline Measures & 1 & 2 & 3 & 4 & 5 \\
\hline (1) Transformational Teaching & 1 & & & & \\
\hline (2) Self Efficacy & 0.26 & 1 & & & \\
\hline (3) Test anxiety & -0.25 & -0.25 & 1 & & \\
\hline (4) Intrinsic Interest & 0.38 & 0.37 & -0.28 & 1 & \\
\hline (5) Critical Thinking & 0.28 & 0.28 & -0.25 & 0.33 & 1 \\
\hline M & 37.76 & 34.62 & 20.62 & 14.91 & 299.55 \\
\hline $\mathrm{Sd}$ & 12.76 & 6.16 & 7.03 & 3.74 & 60.71 \\
\hline Cronbach $\alpha$ & 0.92 & 0.83 & 0.89 & 0.83 & 0.88 \\
\hline
\end{tabular}

Table 1 displays the internal consistencies were acceptable as showed by Cronbach's alpha coefficients. While critical thinking had positive and significant association with Perceived Transformational Teaching, self-efficacy and intrinsic interest, and negative and significant association with test anxiety. In other words, all variables had significant positive relationships with each other (exception of test anxiety). The results of this analysis revealed a good level of model adjustment: $\chi 2(3)=62.65, \mathrm{p}<0.01$; comparative fit index $(\mathrm{CFI})=$ 0.95; Tucker-Lewis index $(\mathrm{TLI})=0.97$; root mean square error of approximation index $(\mathrm{RMSEA})=0.039$. Table 2 shows direct effect measurement parameters, standard error, the critical and significant levels proposed in present study. 
Table 2. Direct effect coefficients

\begin{tabular}{|l|c|c|l|c|c|}
\hline Parameters Directions & B & $\beta$ & S.E & Critical Ratio & $p$ \\
\hline Transformational Teaching to Self Efficacy & 0.128 & 0.266 & 0.024 & 5.339 & 0.001 \\
\hline Transformational Teaching to Test anxiety & -.0139 & -0.252 & 0.027 & -5.093 & 0.001 \\
\hline Transformational Teaching to Intrinsic interest & 0.112 & 0.382 & 0.014 & 8.091 & 0.001 \\
\hline Transformational Teaching to Critical thinking & 0.199 & 0.146 & 0.074 & 2.649 & 0.007 \\
\hline Self efficacy to Critical thinking & 0.407 & 0.144 & 0.138 & 2.941 & 0.003 \\
\hline Test anxiety to Critical thinking & -0.315 & -0.127 & 0.121 & -2.608 & 0.009 \\
\hline Intrinsic interest to Critical thinking & 0.897 & 0.192 & 0.238 & 3.771 & 0.001 \\
\hline
\end{tabular}

The direct relationships of the variables in table 2 show the standard coefficients of transformational teaching to self-efficacy $(\beta=0.26, \mathrm{P}<0.001)$, transformational teaching to test anxiety $(\beta=-0.25, \mathrm{P}<0.001)$, transformational teaching to intrinsic interest $(\beta=0.38, \mathrm{P}<0.001)$, self-efficacy to critical thinking $(\beta=0.14, \mathrm{P}<$ $0.003)$, test anxiety to critical thinking $(\beta=-0.12, \mathrm{P}<0.009)$, and intrinsic interest to critical thinking $(\beta=$ $0.19, \mathrm{P}<0.001$ ) are significant. (See. Figure1).

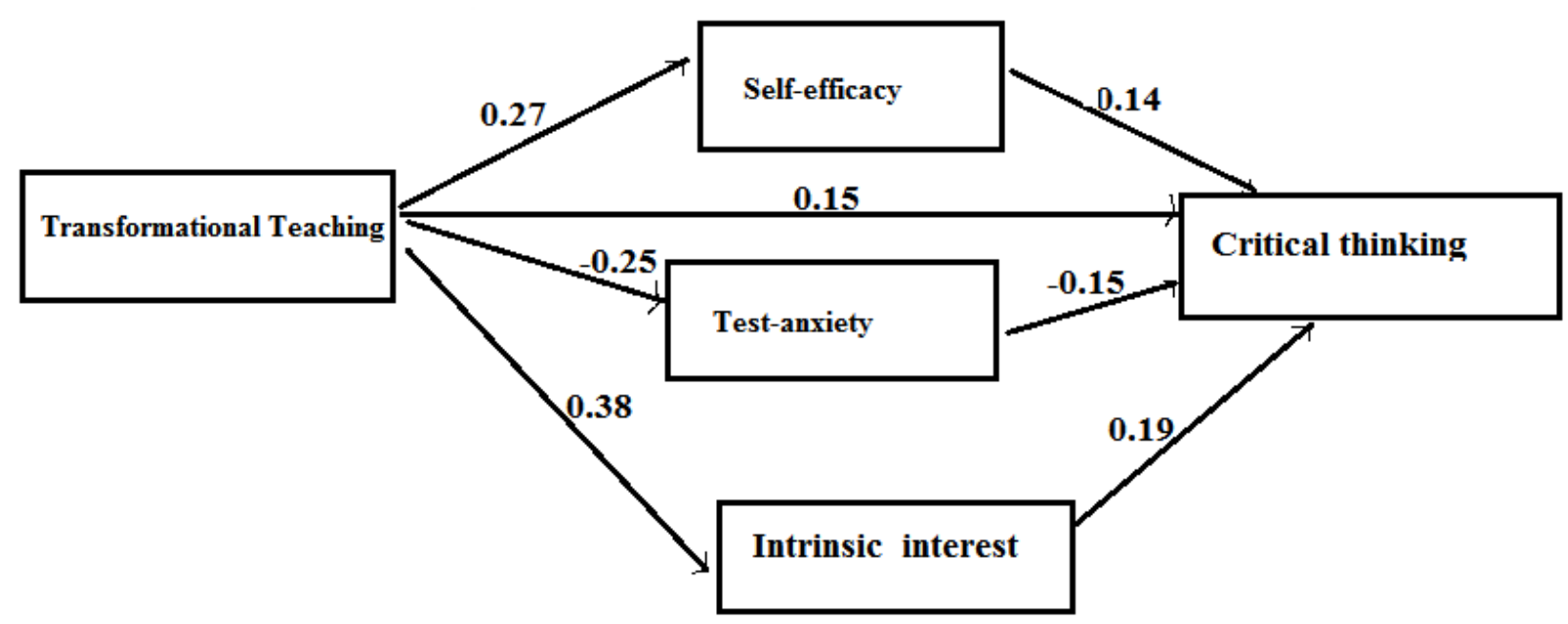

Figure1. Standardized Solution of the Model

The mediation model tested in the present study conceptually denotes Transformational Teaching as an independent variable (X), motivational beliefs as a mediators variable (M), and Critical thinking as a dependent variable (Y).The SPSS script developed by Christopher Preacher from the University of Kansas and Andrew Hays from the Ohio State University (Preacher \& Hayes, 2004) was used to run the mediation analysis and the results are summarized in Table 3. 
Table 3. Indirect effects of IV on DV through proposed mediators

\begin{tabular}{|l|c|c|c|c|c|c|}
\hline Index & Data & Boot & Bias & SE & Low Limit & Upper Limit \\
\hline Total & 0.1964 & 0.1983 & 0.0021 & .0476 & 0.1092 & 0.2956 \\
\hline Self Efficacy & 0.0523 & 0.0537 & 0.0015 & 0.0312 & 0.0016 & 0.1275 \\
\hline Test anxiety & 0.0437 & 0.0429 & -0.0009 & 0.0226 & 0.0036 & 0.0907 \\
\hline Intrinsic Interest & 0.1004 & 0.1019 & 0.0015 & 0.0389 & 0.0301 & 0.1846 \\
\hline
\end{tabular}

Note. $\mathrm{N}=$ 383. 'Data' is the indirect effect calculated in the original sample; 'Boot' is the mean of the indirect effect estimates calculated across all bootstrap samples. "Bias' is the difference between "Data" and "Boot". "SE" is the standard deviation of the bootstrap estimates of the indirect effect

The results of Table 3 revealed that the indirect relationship between transformational teaching and critical thinking through motivational beliefs does not include zero. Therefore, the research hypothesis is confirmed. In other words, the variables (self-efficacy, test anxiety and intrinsic interest) mediate the relationship between the exogenous variable (transformational teaching) and the endogenous variable (critical thinking).

\section{Discussion}

This study developed a model to predict the structural relationship between transformational teaching and critical thinking mediated by motivational beliefs of students. The results confirmed the goodness of fit of the research model. Educational specialists have highlighted the importance of developing students' intellectual skills, and have expressed their deep concerns about students' poor critical thinking abilities. People will think critically when they are motivated or when a balance is created between relevant challenges and supports (Vahedi and Ebrahimi, 2017), because without adequate support and motivation, people will remain inactive in the face of challenges. Critical thinking is careful decision-making, rethinking, and attentive thinking. This meticulous analysis helps individuals achieve valid results, and select the best practices. Dewey argues that critical thinking is a kind of "healthy pessimism" which is different from discovery, interpretation, and determination of events (Veiskarami, Amirian, and Khodaei, 2018).

Critical thinking is mainly concerned with the process of thinking rather than the content of thoughts. Critical thinking is a cognitive activity undertaken to understand findings. Critical thinking includes two aspects of critical thinking skills and critical thinking disposition. One must distinguish between these two aspects; because a person may have adequate critical thinking skills, but he/she may not dare to use those skills. In critical thinking, one identifies the nature of a problem, prepares a solution plan, evaluates relevant feedbacks, and then solves the problem (Seiahi Atabaki, Keshtiaray, and Yarmohammadian, 2016). Thinking is a basic objective in formal education. There is a direct relationship between teachers' teaching styles and learners' critical thinking skills. Passive courses that emphasize memorization of concepts must be replaced by critical thinking-based courses that facilitate learning (Arsal, 2015). Critical thinking requires individuals to develop their analysis and evaluation criteria to enhance the quality of their thinking, and acquire higher levels of knowledge (Zare and Nahravanian, 2017).

Regarding this finding, it can be said that in transformational teaching style, dynamic relationships are established between teachers and students in order to share knowledge and promote students' learning skills and accelerate their personal growth. In this sense, educators are intellectuals who prepare the ground for students to share their knowledge with one another and with their teacher. By playing their traditional role, teachers facilitate students' learning and at the same time try to improve their character and learning skills. Accordingly, they establish a common vision among students, provide them with role models and experiences, 
and challenge their abilities (Sharif, 2014). Effective teaching encompasses general components of teaching and learning. It is also a two-way process, in which students' role is as important as the role played by teacher (Fajari, Sarwanto, and Chumdari, 2020).

In transformational teaching, teaching ways of thinking are far more important than teaching some fixed facts and contents. In fact, in the long run, education must help students learn more easily, master their learning competencies, and use their knowledge and skills more effectively (Ghasemzadeh and Afzali, 2017). Teaching is among the most fundamental educational tools. Many experts believe that teachers' teaching skills and competencies are far more important than other criteria used to select teachers (Karami, Rajaei, and Namkhah, 2014). In student-centered teaching style, teachers take into account students' differences, engage them in the teaching process, and talk with them about relevant problems. In transformational teaching style, teachers increase learners' knowledge of key concepts, transform their attitudes, beliefs, and skills, and create shared knowledge in order to promote students' learning abilities and facilitate their personal growth (Jabbari, 2017).

Declaration of Conflicting Interests: The author(s) declared no potential conflicts of interest with respect to the research, authorship, and/or publication of this article.

Funding: The authors received no financial support for the research, authorship, and/or publication of this article.

Acknowledgements: We are grateful to all the participants who have contributed to this study.

\section{References}

Abdi Ansar, V., Fathi Azar, E., \& Abdollahi, N. (2015), The relationship between critical thinking with creativity, self-efficacy beliefs and academic performance of teacher- students, Journal of Research in School and Virtual Learning, 2, 42-53.

Aharony, N., \& Gazit, T. (2020). Students' information literacy self-efficacy: An exploratory study. Journal of Librarianship and Information Science, 52(1), 224-236.

Al-degether, R. (2009). Teacher educators' opinion and knowledge about critical thinking and the methods they use to encourage critical thinking skills in five female teacher colleges in saudi arabia (Order No. 3352791). Available from ProQuest Dissertations \& Theses Global. (304919096). Retrieved from http:// search.proquest.com/docview/304919096?accountid $=44936$

Arsal, Z. (2015). The effects of microteaching on the critical thinking dispositions of pre-service teachers. Australian Journal of Teacher Education (Online), 40(3), 140

Beauchamp, M. R., Barling, J., Li, Z., Morton, K. L., Keith, S. E \& Zumbo, B. D. (2010). Dvelopment and Psychometric Properties of the Transformational Teaching Questionnaire. Journal of Health Psychology. 15(8) 1123-1134.

Burić, I., and Kim, L. (2020). Teacher self-efficacy, instructional quality, and student motivational beliefs: an analysis using multilevel structural equation modeling. Learn. Instruct. 66,101302. doi: 10.1016/j.learninstruc.2019.101302

Changwong, K., Sukkamart, A., \& Sisan, B. (2018). Critical thinking skill development: Analysis of a new learning management model for Thai high schools. Journal of International Studies, 11(2), 2-11. doi:10.14254/2071-8330.2018/11-2/3

Cheng, L., Cui, Y., Chen, Q., Ye, Y., Liu, Y., Zhang, F., . . Hu, X. (2020). Paediatric nurses' general self-effi- 
cacy, perceived organizational support and perceived professional benefits from Class A tertiary hospitals in Jilin province of China: the mediating effect of nursing practice environment. BMC Health Services Research, 20(1), 12. doi:10.1186/s12913-019-4878-3

De Sousa, F., Rasmussen, I., \& Pierroux, P. (2018). Zombies and ethical theories: Exploring transformational play as a framework for teaching with videogames. Learning, Culture and Social Interaction, 19(December), 40-50. https://doi.org/10.1016/j.lcsi.2018.04.011

Duty, S.M., Christian, L., Loftus, J., \&, Zappi, V. (2016).Is cognitive test-taking anxiety associated with academic performance among nursing students. Nurse Educator, 41(2), 70-74.

Fajari, L. E., Sarwanto, \& Chumdari. (2020). Improving elementary school's critical thinking skills through three different learning media viewed from learning styles. Journal of E-Learning and Knowledge Society, 16(1), 55-65. https://doi.org/10.20368/1971-8829/1135193

Ghasemzadeh, S., \& Afzali, L. (2017). The effectiveness of collaborative teaching on resiliency and transformational teaching for teacher's profession, Quarterly Journal of Career \& Organizational Counseling, 9(31), 26-44.

Hoffman RL, Hudak-Rosander C, Datta J, Morris JB, \& Kelz RR. (2014). Goal orientation in surgical residents: a study of the motivation behind learning. The Journal of Surgical Research. 190 (2), 451-456. DOI: 10.1016/j.jss.2014.01.005.

Jabbari, J. (2017), The relationship between teachers' transformational management and teaching style and students' academic motivation, Master's Thesis, University of Mohaghegh Ardabili, Iran.

Karami, M., Rajaei, M., \& Namkhah, M. (2014), Investigation of tendency toward critical thinking in secondary school teachers and its role on their teaching style, Research in Curriculum Planning, 11, 33-37.

khoshneshin langeroodi, Z. (2015). Validity and reliability of critical thinking ability promotion through E-base environment. Training Measurement, 6 (21), 175-190.

Kusurkar, RA., Croiset, G., \& ten Cate, O. T. J. (2011). Twelve tips to stimulate intrinsic motivation in students through autonomy-supportive classroom teaching derived from self-determination theory. Medical Teacher, 33(12), 978-982. https://doi.org/10.3109/0142159X.2011.599896

Luyten, H., \& Bazo, M. (2019). Transformational leadership, professional learning communities, teacher learning and learner centred teaching practices; Evidence on their interrelations in Mozambican primary education. Studies in educational evaluation, 60, 14-31.

Mavilidi, M. F., Ouwehand, K., Riley, N., Chandler, P. \& Paas, F. (2020). Effects of an acute physical activity break on test anxiety and math test performance. International Journal of Environmental Research and Public Health, 17 (5), 1523-1-1523-13.

McDonald, A.S. (2001). The prevalence and effects of test anxiety in school children. Educational psychology, 21(1), 89-101.

McEnroe-Petitte, D., \& Farris, C. (2020). Using Gaming as an Active Teaching Strategy in Nursing Education. Teaching and Learning in Nursing, 15, 61-65. doi:10.1016/j.teln.2019.09.002

Mustafa, G., Glavee-Geo, R., Gronhaug, K., \& SaberAlmazrouei, H. (2019). Structural impacts on forma-tion of self-efficacy and its performance effects.Sustainability,11(3), 860. doi:10.3390/su11030860

Niemiec, C. P., Ryan, R. M., \& Deci, E. L. (2010). Self-determination theory and the relation of autonomy to self-regulatory processes and personality development. In R. H. Hoyle (Ed.), Handbook of personality and 
self-regulation (p. 169-191). Wiley-Blackwell. https://doi.org/10.1002/9781444318111.ch8

Pai, H. C., Eng, C. J., \& Ko, H. L. (2013). Effect of caring behavior on disposition toward critical thinking of nursing students. Journal of Professional Nursing 29(6): 423-429. doi: 10.1016/j.profnurs.2012.05.006.

Pintrich, P. R., \& De Groot, E. V. (1990). Motivational and self-regulated learning components of classroom academic performance. Journal of Educational Psychology, 82(1), 33-40. https://doi.org/10.1037/00220663.82.1.33

Popil, I. (2011). Promotion of critical thinking by using case studies as teaching method. Nurse Education Today., 31(2), 204-207.

Preacher, K. J., and Hayes, A. F. (2008). Asymptotic and resampling strategies for assessing and comparing indirect effects in multiple mediator models. Behavior Research Methods,40, 879-891. https://doi. org/10.3758/BRM.40.3.879

Saheb Alzamani, M., \& Zirak, A. (2011). Students‘ Learning and Study Strategies in Isfahan University of Medical Sciences and their relationship with Test Anxiety. Iranian Journal of Medical Education, 11(1), $58-68$.

Samadi, M. (2012). Relationship between motivational orientation and learning strategies in predicting academic success. Bimonthly of Education Strategies in Medical Sciences, 5(2), 105-111.

Samavi, S.A., and Najjarpourian, S. (2019). The causal relationship between internal motivation, academic engagement and academic self-regulation with academic performance mediated by self-directed learning in high school students in Bandar Abbas. Cognitive Strategies in Learning, 7(12), 47-68. doi:10.22084/j. psychogy.2018.15114.1682

Seiahi Atabaki, A.M., Keshtiaray, N., \& Yarmohammadian , M.H. (2016). Investigating students' experiences from teaching based on developing critical thinking, Journal of New Approach in Educational Administration, 7(25), 99-117.

Soltani arabshahi, K., Norouzi, A., Norouzi, S., \& Cid, L. (2014). Examining the psychometric characteristics of tools for measuring intrinsic motivation inventory and perceived motivational climate scale among medical students. Iranian Journal of Medical Education; 13 (12), 1114-1126.

Stewart, G., Seifert, T. A., \& Rolheiser, C. (2015). Anxiety and Self-efficacy's Relationship with Undergraduate Students' Perceptions of the use of Metacognitive Writing Strategies. The Canadian Journal for the Scholarship of Teaching and Learning, 6(1). https://doi.org/10.5206/cjsotl-rcacea.2015.1.4.

Vahedi, V. S., \& Ebrahimi, M. (2017). The effectiveness of critical thinking skill training on iranian efl learners' reading comprehension and reading strategy use. Instruction Technology, 11(2), 171-180. DOI: $10.22061 /$ tej.2017.636

Veiskarami, H., Amirian, L., \& Khodaei, S. (2018). The Effectiveness of Critical Thinking Training on the Happiness and Tolerance of Ambiguity in Medical Students. Research in Medical Education, 10(3), 5866. doi:10.29252/rme.10.3.58

Zare, H., \& Nahravanian, P. (2017). The effect of training on problem-solving style and self-directed learning. Advances in Cognitive Sciences, 19(2), 85-96.

Zhang. J., \& Chen, B. (2020). The effect of cooperative learning on critical thinking of nursing students in clinical practicum: A quasi-experimental study. Journal of Professional Nursing, https://www.X-mol. com/paperRedirect/1266477422116642816 